\title{
PERMANÊNCIA PARA ALÉM DA PRECARIZAÇÃO DO TRABALHO: a centralidade das trabalhadoras terceirizadas para a funcionalidade do Instituto Federal da Paraíba/campus João Pessoa
}

\author{
PERMANENCE BEYOND PRECARIOUS WORK: the centrality of outsourced \\ workers to the functionality of the Federal Institute of Paraíba campus João Pessoa
}

Marcelo Cadore*

\section{Resumo}

$\mathrm{O}$ presente artigo procura desvelar como trabalhadoras terceirizadas que atuam no Instituto Federal da Paraíba/campus João Pessoa (IFPB-JP), situado no Bairro Jaguaribe, permanecem por longos períodos em seus postos de trabalho mesmo com a rotatividade das empresas prestadoras de serviços. Para tanto, em um primeiro momento, o texto traz algumas particularidades no mundo do trabalho na América Latina e no Brasil, e também como a sociologia do trabalho se coloca diante desses desafios históricos, e em seguida, partindo do pressuposto de que a terceirização é uma forma de subcontrato trabalhista, portanto uma condição estruturalmente precarizada, o artigo busca destacar e contextualizar politicamente os principais marcos da construção do atual (2020) arcabouço jurídico dessa modalidade de vínculo empregatício. $\mathrm{Na}$ sequência, é apresentado um estudo de caso no IFPB-JP que demonstra como a centralidade das atividades desenvolvidas por trabalhadoras terceirizadas garantem a funcionalidade da instituição escolar como um todo, e como isso se configura em um dos aspectos que asseguram a continuidade em seus empregos por períodos longevos. Por fim, o presente trabalho argumenta a necessidade de classificar essas trabalhadoras terceirizadas como profissionais da educação e da imperiosa urgência na elaboração de políticas compensatórias para sanar a defasagem existente em relação aos servidores estatutários. Medidas estas que também servem como desincentivo aos crescentes processos de terceirização dentro do serviço público.

Palavras-chave: Trabalhadoras; Terceirização; Funcionalidade; Permanência.

\begin{abstract}
This article seeks to reveal how outsourced workers who work at the Federal Institute of Paraíba/campus João Pessoa (IFPB-JP), located in Bairro Jaguaribe, remain for long periods in their jobs even with the turnover of service providers. Therefore, at first, the text brings some particularities in the world of work in Latin America and Brazil, and also how the sociology of work is faced with these historical challenges and then, starting from the assumption that outsourcing is a form of labor subcontract, therefore a structurally precarious condition, this article seeks to highlight and contextualize politically the main milestones of the construction of the current (2020) legal framework
\end{abstract}

\footnotetext{
* Aluno do Curso de Licenciatura em Ciências Sociais da UFPB/Brasil. E-mail: marcelocadorecs@gmail. com.
} 
of this type of employment relationship. Following, a case study is presented at the IFPBJP that demonstrates how the centrality of the activities developed by outsourced workers guarantee the functionality of the school institution as a whole, and how this is configured in one of the aspects that ensure continuity in their jobs for long-lived periods. Finally, this paper argues the need to classify these outsourced workers as education professionals and the imperative urgency in the elaboration of compensatory policies to remedy the existing gap in relation to statutory employees. These measures also serve as a disincentive to the growing outsourcing processes within the public service.

Keywords: Female Workers; Outsourcing; Functionality; Permanence.

\section{Introdução}

O trabalho tem sido ao longo da história uma categoria social importante para explicar fenômenos e acontecimentos que marcaram e marcam sensivelmente a organicidade societal. Ele tem tomado as mais diversas formas de realização de acordo com o momento histórico em que está contextualizado, com as configurações que o modo de produção das necessidades materiais dos sujeitos que constituem a sociedade está sistematizado, e de como o Estado reage às pressões oriundas da luta de classes que vão refletir na regulamentação jurídica trabalhista. Nesse cenário, a terceirização da força de trabalho tem sido uma técnica cada vez mais recorrente em todos os meios, inclusive no campo da educação.

Ao se reportar a um tema sob uma perspectiva universalista e abstrata, limita-se muito a possibilidade de verificar as particularidades desse mesmo tema na sua aplicação cotidiana, na sua dimensão empírica de realização. Para tentar preencher essa lacuna, este estudo procura, dentro dos limites de suas possibilidades, dimensionar, de forma genérica, como a categoria social trabalho, mais especificamente a modalidade de subcontrato trabalhista conhecida como terceirização, e o modo como se realiza em nossa sociedade, têm um alcance universalizado, porém com repercussões diferentes sobre os diversos grupos/dimensões sociais/políticos presentes no meio societal.

Portanto, o presente estudo estará divido em quatro principais partes: a primeira tratará do mundo do trabalho na América Latina e no Brasil, abordando algumas particularidades da região e como a sociologia do trabalho se portou diante desses desafios; a segunda parte foi pensada para mostrar os marcos históricos e contextos políticos percorridos para a regulamentação do trabalho terceirizado no Brasil; a terceira 
será um estudo de caso dentro do IFPB, que demonstra casos de permanência de trabalhadoras terceirizadas no mesmo emprego por extensos períodos, apesar da contínua precarização das condições do mundo do trabalho; e por fim, a quarta parte deste estudo apresenta os resultados e conclusões obtidos.

\section{0 trabalho na América Latina e no Brasil}

A América Latina possui particularidades que não podem ser esquecidas quando observamos o mundo do trabalho. O recente passado escravocrata, as bases econômicas colonialistas, a latente dependência econômica e tecnológica junto aos países centrais do capital corroboram para um cenário de desalento para a classe trabalhadora e propício para o despotismo de classe burguês. A instabilidade política, a submissão das burguesias nacionais frente às burguesias globais, a miséria estrutural e sistêmica, assim como as diversas formas de preconceitos (gênero, raça, classe, religião, território etc.) também são elementos que compõem essa realidade local. Em meio a essa correlação de forças tão díspares e assimétricas, o mundo do trabalho na América Latina é marcado pela precariedade e pelo regime de superexploração da mão-de-obra (MARINI, 2005).

Ao longo do tempo, a sociologia do trabalho tem buscado entender e mesmo colaborar para a superação desses problemas que afligem nossa existência até os tempos atuais.

No artigo de Laís Abramo intitulado Desafios atuais da sociologia do trabalho na América Latina: algumas hipóteses para a discussão, publicado em 1999, a pesquisadora argumenta que a sociologia do trabalho na América Latina tem um caráter militante, não por ser partidária, mas por andar em compasso com os temas que marcaram, nos distintos períodos, os desafios colocados pelos atores sociais e políticos no plano geral da sociedade. Nas décadas de 50 e 60, a temática central era a modernização, nas décadas de 70 e 80 era o embate democracia vs. Ditadura, e já nos anos 90, era o ajuste estrutural e a globalização (ABRAMO, 1999).

A professora Marcia de Paula Leite escreve A sociologia do trabalho na América Latina: seus temas e problemas (re)visitados, em 2012, apontando como durante os anos 2000, países como Argentina e Brasil construíram um modelo de desenvolvimento inclusivo e desconcentrador de renda, conseguindo fomentar um mercado interno que 
gerou novos postos de trabalho, em grande parte precários, é verdade (LEITE, 2012). A autora chega a fazer um alerta na conclusão de seu estudo afirmando que, apesar do cenário positivo daquele momento (2011) revelar certos ganhos para a sociedade, “[...]isso não significa que ela não apresente um conjunto de problemas a serem enfrentados sob pena de o atual processo significar nada mais do que um curto período em que nossos países se demonstraram capazes de aproveitar um momento internacional favorável" (LEITE, 2012, p. 119).

Esse cuidado deve ser redobrado em regiões como a América Latina, sobretudo no Brasil, em virtude do histórico processo de crescimento econômico com aumento da desigualdade.

Após essa última publicação, o Brasil passou por profundas alterações no mundo do trabalho com um alto crescimento da taxa de desemprego, um golpe político que retirou uma presidenta eleita democraticamente, reforma trabalhista, lei da terceirização irrestrita, a Emenda Constitucional 95 que congela os gastos públicos por até 20 anos e a eleição de um governo com perfil de extrema-direita, preconceituoso, policialesco, persecutório e fascista por um lado, e por outro, neoliberal defensor de um Estado mínimo para as garantias e proteções sociais, mas disposto a socorrer a classe burguesa (empresarial e latifundiária) ao sinal de qualquer descontentamento mínimo por parte desses últimos. Dessa forma, seria plausível indicar que durante os anos 2000, a temática central da sociologia do trabalho no Brasil orbitaria em torno do novo modelo de desenvolvimento inclusivo e desconcentrador de renda, e nos anos de 2010, a centralidade dos estudos focaria nas novas formas de precarização do mundo do trabalho e das relações trabalhistas.

Urge destacar que, ao lado dos pontos já avultados nos parágrafos anteriores, principalmente após a década de 1980, pesquisas sobre o trabalho e suas intersecções com o gênero e raça ganharam mais visibilidade no meio científico. Esses estudos analisam o entrelaçamento de tais categorias (trabalho, gênero e raça), desvelando os arranjos sociais responsáveis pela criação de um lugar subalterno destinado a mulheres e negros nas estruturas sociais da composição do mercado de trabalho. Essa abordagem é apresentada por competentes autoras que seguem desenvolvendo investigações minuciosas sobre o tema, seguindo diversas nuances de complexidade, podendo ser verificadas nos trabalhos 
de Abramo (2006), Nogueira e Passos (2018), Proni e Gomes (2015), Santos e colaboradoras (2014), entre outros.

\section{Reestruturação produtiva do capital, contexto político e terceirização: caminhos para precarização do trabalho no Brasil}

No Brasil, o impulso para a reestruturação produtiva do capital foi a crise da dívida externa de 1981, onde o governo do general Figueiredo, com base em políticas econômicas orientadas pelo Fundo Monetário Internacional (FMI), incentivou as exportações dando um choque de competitividade nas grandes empresas instaladas no país, fazendo com que elas adotassem, ainda que de maneira parcial, novos padrões organizacionais tecnológicos, principalmente focando na automação do setor produtivo e no controle de qualidade. Esse primeiro momento da reestruturação produtiva do Brasil é marcado pela vigência do chamado toyotismo restrito (ALVES, 2000), e concentra-se principalmente nas grades montadoras do ABC paulista, tendo como principal agente de resistência o Sindicato de Metalúrgicos do ABC e a CUT - Central Única dos Trabalhadores (ANTUNES, 2011).

Contudo, a partir da década de 1990 é que as demais mudanças necessárias para a efetivação do toyotismo se intensificam no Brasil, abrindo campo para uma nova expansão das atividades terceirizadas. Principalmente, no período em que Fernando Henrique Cardoso presidiu o país, se inseriu um forte processo de desregulamentação do trabalho, com a criação das cooperativas profissionais, restrição do direito de greve no setor público e o fim das indexações salariais (OLIVEIRA, Roberto, 2015). Pelo uso do sistema just in time/Kanban, o aperfeiçoamento dos Programas de Qualidade Total e dos Círculos de Controle Total e, principalmente, por meio da desregulamentação e flexibilização dos contratos e legislações trabalhistas, esse período passou a ser denominado como toyotismo sistêmico (ALVES, 2000). Importante ressaltar que esse momento é marcado por intensa oposição dos setores mais combativos do movimento sindical, com viés classista e que ainda não tinham aderido ao conhecido peleguismo ${ }^{1}$,

\footnotetext{
1 “A expressão vem da palavra 'pelego', peça de lã de carneiro que se coloca sobre a sela de montaria para torná-la mais confortável para o cavaleiro. O pelego sindical, em geral um operário, embora a expressão também possa ser aplicada aos patrões, era aquele funcionário que procurava beneficiar-se do sistema, bajulando o governo e o empregador e negligenciando a defesa dos interesses da classe" (CARVALHO, 2012, p. 122).
} 
destacando-se a greve dos petroleiros em 1995 que durou 31 dias e foi fortemente reprimida pelo governo FHC, inclusive com o uso das forças armadas (ANTUNES, 2011).

\subsection{Terceirização: o subcontrato made in Brazil}

O termo "terceirização" foi utilizado pela primeira vez no Brasil em inícios da década de 1970 por Aldo Sani, engenheiro e superintendente da Riocell, empresa do ramo da celulose situada em Guaíba (RS), como um neologismo de origem no latim terciariu. Ao que tudo indica, a expressão só é utilizada no Brasil mesmo, já que em outros países geralmente é empregado o termo subcontratação (MARCELINO; CAVALCANTE, 2012).

Na literatura científica da área, a terceirização é apontada como a principal forma de precarização do trabalho formal no Brasil (MARCELINO; CAVALCANTE, 2012; OLIVEIRA, Ricardo, 2018; OLIVEIRA, Roberto, 2015). Isso decorre da

[...] tendência de precarização das condições de trabalho com o advento das terceirizações, o que se evidencia em perda salarial e de direitos, aumento da intensidade do trabalho e dos riscos à saúde do trabalhador, além de dificuldades enfrentadas pelos sindicatos para unificar as lutas comuns (MARCELINO; CAVALCANTE, 2012, p. 332).

A terceirização já vinha sendo praticada dentro dos marcos da legalidade e da regulamentação no Brasil desde o fim da década de 1960. O parágrafo $7^{\circ}$ do Artigo 10 do Decreto-lei 200, de 25 de fevereiro de 1967 (BRASIL, 1967), passou a autorizar a contratação de empresa, nesse caso, somente pela administração pública, para a realização de tarefas de planejamento, coordenação, supervisão e controle, desde que com contrato de prazo máximo igual ou inferior a três meses (DIEESE, 2017). Para além desse prazo, era necessária uma autorização do Ministério do Trabalho e Emprego da localidade em que o órgão público se situava.

Outros marcos importantes no processo de regulamentação do trabalho terceirizado foram a Lei 6.019 de 03 de janeiro de 1974 (BRASIL, 1974), que autorizava a contratação de trabalho temporário, limitado a 90 dias, e para alguns casos específicos, mas sem a mesma proteção legal/jurídica de uma trabalhadora com contrato direto, e a Lei 7.102 de 20 de junho de 1983 (BRASIL, 1983), pela qual as empresas de serviços de 
vigilância e de transporte de valores obtiveram amparo para realizarem suas atividades como terceirizadas (OLIVEIRA, Roberto, 2015).

O uso da modalidade de terceirização ganhou espaço com o passar do tempo, e rapidamente a justiça do trabalho viu-se repleta de processos movidos por trabalhadoras e sindicatos que buscavam sanar as desigualdades e demais desvantagens que a terceirização provocava no mundo do trabalho. Com vistas a pacificação desses conflitos, em 21 de dezembro de 1993 é publicada a Súmula 331 do Tribunal Superior do Trabalho (TST), que regia sobre a locação de mão-de-obra, terceirização, contrato de prestação de serviços, legalidade e responsabilidade subsidiária do tomador de serviço, revisando a Súmula 256/TST, a Lei 6.019/1974, a Constituição Federal de 1988 no parágrafo II do artigo 37, a Lei 7.102/1983, a Lei 8.666/1993 no artigo 71, Decreto-lei 200/1967 no artigo 10, parágrafo $7^{\circ}$, e por fim, o artigo $3^{\circ}$, parágrafo único, da Lei 5.645/1970. Esse entendimento foi revisitado pelo próprio pleno do TST, e por ele mantido em 28 de outubro de 2003. Em maio de 2011, o pleno inclui mais três parágrafos na redação da súmula, que tratam da responsabilidade subsidiária de empresas contratantes em alguns casos específicos (BRASIL, 1993).

Em síntese, no que diz respeito ao trabalho terceirizado, o que a Súmula 331 propôs foi uma divisão no interior das empresas em dois segmentos de atividades, as atividades meio e as atividades fim. Essa polêmica decisão serviu de orientação para os tribunais de todo o país, e tinha no seu parágrafo III, as abordagens mais sensíveis quanto à terceirização, dizendo que:

\footnotetext{
Não forma vínculo de emprego com o tomador a contratação de serviços de vigilância (Lei 7.102, de 20/06/83), de conservação e limpeza, bem como a de serviços especializados ligados à atividade-meio do tomador, desde que inexistente a pessoalidade e a subordinação direta (BRASIL, 1993).
}

A falta de uma definição precisa sobre o que é uma e outra atividade, bem como o entendimento de que uma regulamentação que implica em alteração ou criação de novas leis deve ser elaborada e conduzida nas casas legislativas e não na esfera do judiciário, além das pressões exercidas por sindicatos combativos para impedir o avanço dessa forma precária de trabalho de um lado, somadas às pretensões das entidades patronais burguesas, por outro lado, que buscavam novas alternativas para aumentar sua competividade e se 
enquadrar nos moldes da "empresa enxuta", fizeram com que projetos de lei fossem elaborados e discutidos nos âmbitos dos poderes executivos e legislativos da federação.

Em resposta ao fato descrito no parágrafo anterior, a Lei 8.863 de 28 de março de 1994 ampliou a permissão para contratação de empresa terceirizada em setores de vigilância patrimonial na esfera pública e privada, e ainda na esteira das reformas que viabilizariam a implementação do toyotismo sistêmico no Brasil (ALVES, 2000), a reforma administrativa (PEC 41/97), instituiu a terceirização de atividades na Administração Pública direta e indireta (OLIVEIRA, Roberto, 2015).

Fernando Henrique Cardoso, então Presidente da República, em 1998 encaminha à Câmara o PL 4302 que tinha como objetivo alterar a Lei 6.019/1974, que regulamentava o trabalho temporário, mas incluía um parágrafo para normatizar a intermediação de mão de obra por empresas interpostas nos processos de terceirização. O PL 4302/1998 foi engavetado no Congresso Nacional em 2003 após apelo das centrais sindicais ao governo Lula, que por meio da Mensagem n 389 transmitiu a reivindicação das centrais sindicais para o Legislativo Federal. No ano seguinte, Sandro Mabel, na época deputado pelo então PMBD (atualmente MDB) de Goiás, apresenta, o PL 4330 que, em sintonia com a Súmula 331/TST, propõe a regulamentação da terceirização mantendo a divisão entre atividades meio e atividades fim, com o intuito de minimizar as ações trabalhistas por meio da definição legal e precisa dessa questão (OLIVEIRA, Roberto, 2015; OLIVEIRA, Ricardo, 2018).

Em 2007, na Câmara Federal, o PL 1621 foi proposto por Vicentinho, antigo líder sindical da CUT, e na época deputado federal pelo Partido dos Trabalhadores (PT) de São Paulo. O PL 1621 reivindicava a proibição da terceirização em atividades fim, a igualdade de direitos entre trabalhadoras terceirizadas e trabalhadoras contratadas diretamente pela empresa, assim como a responsabilidade "solidária" da contratante. Esse Projeto foi anexado ao PL 4330/2004 pela Mesa Diretora da Câmara dos Deputados, em novembro de 2013, deferindo o Requerimento $n^{\circ} 8959 / 2013$, por se tratar de matéria correlata (OLIVEIRA, Ricardo, 2018).

Em 2015, primeiro ano do segundo mandato da presidenta Dilma Rousseff, a situação política no país estava muito instável. Em parte, isso se explica porque na votação do pleito presidencial que fora realizada no dia 5 de outubro de 2014, Dilma 
Rousseff do PT e Aécio Neves do PSDB sagram-se vencedores em primeiro e segundo lugares respectivamente, partindo assim, os dois para o segundo turno das eleições presidenciais. A segunda votação ocorreu no dia 26 de outubro e consagrou a vitória petista, porém com uma vantagem muito pequena, a menor diferença percentual da história das disputas para o cargo majoritário de nossa república, uma margem muito apertada de 3,28\%. Aécio Neves e o PSDB recorreram à justiça eleitoral de diferentes formas, solicitando recontagem dos votos e ingressando com uma ação que exigia a anulação da vitória de Dilma, alegando abuso de poder político e econômico durante a campanha, o que na prática significa o não reconhecimento da derrota por parte do candidato tucano, expediente esse que pode ser chamado de "udenismo".

A crise econômica, que se asseverava de forma preocupante, favorecia a disseminação de ideias neoliberais como solução para as dificuldades que se avolumavam. Urge apontar que nesse momento, o país estava passando por sérias dificuldades. A deterioração financeira assola boa parte da população brasileira, os preços de alimentos elevaram-se, assim como outras despesas primárias como energia elétrica e combustíveis, as taxas de desemprego começam a subir e de maneira muito alarmante. A crise política passa a ganhar traços dramáticos com o avanço persecutório, nitidamente "udenista", da operação Lava-Jato e a desorganização da base política do governo, minada por interesses patronais e ausente de quaisquer projetos que não fosse do interesse das elites. Um plano de ajuste fiscal proposto por Joaquim Levy, então Ministro da Fazenda, com medidas duras de contingenciamento de gastos em áreas de assistência social, desagrada à base política e social mais leal à presidenta e seu partido, o que também colabora para a piora do quadro apresentado.

No dia 2 de dezembro de 2015, Eduardo Cunha (PMDB/RJ) autoriza a apreciação do processo de impeachment da presidenta Dilma por parte da Câmara dos Deputados. No dia 17 de abril de 2016, em uma seção fatídica, a Câmara Federal dos Deputados votou pelo prosseguimento do processo de impedimento de Dilma Rousseff, tudo acompanhado e amplamente divulgado pela mídia em conluio com atores protagonistas do golpe. Mesmo com o cenário nebuloso e tenso que se desenhava nos rumos políticos do país, o Senado aprovou, por 55 votos a favor e 22 contra, a admissibilidade do processo de impeachment da presidenta Dilma Rousseff, no dia 12 de maio de 2016, e em votação 
no dia 31 de agosto de 2016, o Senado cassa o mandato da presidenta Dilma, com 60 votos contra 21.

Michel Temer assume a Presidência da República com um discurso de realização de "reformas" econômicas para "modernizar" a economia do país, recorrendo à retórica eufemística típica dos neoliberais. A Mensagem no 389 , redigida pela Presidência da República e destinada à Presidência do Congresso Nacional, que requeria o arquivamento do PL 4302/1998, nunca foi referendada no poder legislativo, permitindo o projeto a tramitar novamente. O governo Michel Temer, juntamente com o Presidente da Câmara, Rodrigo Maia (DEM/RJ) pautou o PL 4302/1998, sendo votado e aprovado no plenário em 22 de março de 2017, por 231 votos a favor, 188 votos contra e 8 abstenções. O projeto, por ter sido votado e aprovado no Senado ainda em 2002, foi diretamente à sanção presidencial, convertendo-se na Lei Ordinária 13.429/2017, com publicação no Diário Oficial da União em 31 de março de 2017 (OLIVEIRA, Ricardo, 2018). Após esses trâmites políticos, ainda houve a judicialização da referida lei, porém, o pleno do Supremo Tribunal Federal, nesse caso em total harmonia com os poderes legislativo e executivo, julgou e declarou no dia 30 de agosto de 2018 a constitucionalidade da Lei 13.429/2017, o acórdão foi publicado no dia 11 de outubro de 2018.

Observando o modus operandi e o contexto político/econômico/social em que a terceirização foi regulamentada no Brasil, fica evidente o quanto esse fato foi uma derrota para a classe trabalhadora frente à classe patronal. A formatação da Lei 13.429/2017 (rege os contratos temporários e permite a terceirização irrestrita) e da Lei 13.467/2017 (reforma trabalhista) permitem as empresas atacarem os já parcos direitos trabalhistas, sendo por meio da redução do valor da força de trabalho, externalização de conflitos trabalhistas, ou dificultando o acesso à justiça do trabalho. Isso corrobora com a definição de terceirização proposta por Marcelino e Cavalcante (2012):

\begin{abstract}
terceirização é todo processo de contratação de trabalhadores por empresa interposta, cujo objetivo último é a redução de custos com a força de trabalho elou a externalização dos conflitos trabalhistas. Ou seja, é a relação na qual o trabalho é realizado para uma empresa, mas contratado de maneira imediata por outra (MARCELINO; CAVALCANTE, 2012, p. 338, grifo dos autores).
\end{abstract}

A derrota que a classe trabalhadora sofreu com a regulamentação da terceirização irrestrita deve ser observada com muita atenção, já que a repercussão no interior da classe se dará com maior intensidade em grupos que historicamente ocupam posições mais 
vulneráveis na composição do mercado de trabalho, notadamente a população negra e as mulheres.

O próprio caminho percorrido até a regulamentação atual da terceirização da força de trabalho acabou por moldar o mercado que se apropria desse nicho econômico. Como somente uma parte das atividades pôde ser terceirizada até recentemente - 2017 -, as vagas destinadas a essas trabalhadoras estão concentradas em setores de segurança privada, limpeza e asseio, manutenção de estruturas, apoio logístico e apoio administrativo.

\section{Terceirização no IFPB-JP: a centralidade das servidoras terceirizadas para o funcionamento da instituição ${ }^{2}$}

Com o processo de reestruturação produtiva do capital e o avanço de políticas de cunho neoliberal iniciados ainda na década de 1980, o Estado brasileiro passou por transformações substanciais, especialmente no que tange à composição de sua força de trabalho. Essas mudanças na Administração Pública, que competem às obrigações trabalhistas decorrentes da terceirização, estão presentes no IFPB-JP. Por isso, o quadro que compõe a estrutura funcional da instituição deve não ser entendido apenas com os servidores públicos, mas com a decisiva participação dos setores terceirizados na administração do ambiente escolar.

O IFPB, conforme dados disponibilizados por seu Departamento de Apoio à Administração (DAA), conta atualmente com 2164 funcionários contratados diretamente, sejam estatutários ou celetistas, sendo 1149 docentes e 1015 técnicos administrativos, distribuídos entre os 15 campus da instituição e a reitoria. O Campus João Pessoa é de longe o que possui o maior quadro de lotação de servidores, são 595, o que representa $27,49 \%$ do total de servidores contratados diretamente pelo IFPB. Destes 595 lotados em João Pessoa, 372 são docentes, ocupando 62,52\% do quadro de servidores públicos do campus João Pessoa, e 16,82\% em relação aos Institutos Federais do Estado como um todo, enquanto 223 são técnicos administrativos e representam $37,48 \%$ dos servidores públicos do Campus João Pessoa, e 10,30\% em relação ao Estado.

\footnotetext{
${ }^{2}$ Os nomes reais dos trabalhadores e trabalhadoras, citados no texto, foram substituídos por nomes fictícios a fim de proteger suas identidades.
} 
Contudo, esses dados incluem apenas os trabalhadores que estão contratados diretamente pelo IFPB e, portanto, desconsideram uma importante parcela do capital humano que diariamente contribui para o funcionamento do órgão público. Trata-se das trabalhadoras terceirizadas, contratadas pelo regime CLT por empresas prestadoras de serviços.

Segundo o DAA do IFPB, existem hoje duas empresas prestadoras de serviços atuando no instituto. São elas a ZÊLO LOCAÇÃO DE MÃO DE OBRA EIRELI com 68 trabalhadores auxiliando no setor administrativo, e a empresa CLAREAR COMÉRCIO E SERVIÇOS DE MÃO DE OBRA - EIRELI, que conta com 81 trabalhadores no IFPB, sendo 59 no setor da limpeza, e os 22 restantes como intérpretes da Língua Brasileira de Sinais (LIBRAS). A regulamentação jurídica à essa prestação de serviços está regida nos contratos de $n^{\circ} 09 / 2016, n^{\circ} 11 / 2016$ e $n^{\circ} 01 / 2017$. Dessa forma, podemos verificar que o quadro geral dos trabalhadores dentro do IFPB/JP, soma dos contratos diretos e terceirizados, é de 744 trabalhadores. Deste total 149 (20,02\%) são terceirizados e 595 $(79,98 \%)$ contratados diretamente pelo Instituto.

Olga é secretária no Departamento de Apoio à Administração, função que exerce desde 9 de outubro de 2009, ou seja, há mais de dez anos. Ela começou a trabalhar no IFPB-JP sendo vinculada à empresa JMT SERVICOS DE LOCAÇÃO DE MÃO DE OBRA LTDA. Ao findar o contrato da JMT com o Instituto, ela rescindiu com a prestadora de serviços e passou a ser funcionária da LOTUS EMPREENDIMENTOS E SERVICOS LTDA - ME, então vencedora da licitação promovida para contratação de serviços terceirizados. Ao acabar mais esse contrato, Olga encerra seu vínculo com a Lótus e imediatamente assina sua CTPS $^{3}$ junto a ZÊLO LOCAÇÃO DE MÃO DE OBRA EIRELI, onde permanece, ao menos até o fim da elaboração deste estudo.

A função desenvolvida por Olga é de suma importância para o funcionamento de praticamente todas as atividades realizadas no IFPB-JP. Ela é responsável por organizar a agenda do prefeito do campus, das empresas que prestam serviço para a instituição, além de ter acesso a toda documentação que circula nesse setor, que é responsável direto pela gestão dos serviços gerais, transportes, serviços gráficos, infraestrutura, manutenção, conservação e segurança do instituto. É notório que sem o andamento dessas atividades

\footnotetext{
${ }^{3}$ Carteira Nacional de Trabalho e Previdência Social
} 
torna-se impossível ministrar as aulas ou quaisquer outras práticas do campo da Educação, como pesquisa e extensão, por não haver disponibilidade de infraestrutura mínima necessária.

Olga é auxiliada por outra secretária com quem divide o ambiente de trabalho, a antessala do prefeito do campus, a maior parte do tempo. Silveira, o supervisor responsável pela empresa Zêlo também ocupa essa mesma sala de forma esporádica, já que sua função exige trânsito pelos diversos setores do IFPB. Na ocasião em que Silveira foi interpelado sobre a importância que essas trabalhadoras têm para a comunidade escolar e acadêmica citada, ele foi taxativo ao afirmar que "sem essas duas cabeças tudo para, pode fechar o IF."

Quando questionada sobre sua permanência no cargo apesar das substituições das empresas prestadoras de serviços, Olga afirmou que esse fato é em decorrência do bom trabalho que vem sendo realizado por ela, e que isso, por si só, gera um sentimento gratificante em relação a sua condição de trabalhadora. Também deixa nítida sua vontade de seguir trabalhando no IFPB-JP ao afirmar que "já estou na terceira empresa aqui, e se Deus quiser vou para a quarta." Cabe destacar que Olga tem plena consciência da existência de diferenças significativas entre sua condição de funcionária terceirizada e a de outras trabalhadoras da mesma área que ingressaram por concurso público e são servidoras estatutárias, diferenças essas que vão desde questões salariais até o direito assegurado de estabilidade no emprego.

Marli trabalha no IFPB-JP há 31 anos, sendo contratada, segundo ela, por "cinco ou seis empresas diferentes" nesse período, é responsável por fazer o café que é distribuído no horário do intervalo nas áreas de convivência do campus. Em torno do seu ambiente de trabalho, e mesmo nos locais onde o café preparado por Marli é levado, são espaços de intensa sociabilidade de todos os integrantes da comunidade escolar e acadêmica. É nesses horários e locais que estudantes de diferentes cursos, técnicos administrativos, servidoras terceirizadas e professoras se encontram, de forma planejada ou por acaso, se reúnem para falar sobre a política, o trabalho, a família, os estudos, e enfim, toda sorte de assuntos que circulam por pessoas de diferentes estratos sociais, graus de escolaridade, religião, gênero, orientação sexual e raça, entre outros tantos marcadores sociais. 
Esse ambiente externo a sala de aula, que sugere uma maior espontaneidade dos integrantes do meio escolar, não só pode como deve ser um espaço utilizado pela gestão da comunidade escolar e acadêmica para intensificar o processo de formação de cidadãos tolerantes e democráticos, capazes de produzir alteridades fundamentadas no respeito mútuo e na convivência positiva com as diferenças, construindo uma perspectiva crítica de conhecimento coletivo que transborda as fronteiras delimitadas pelo IFPB-JP, e têm reflexos diretos na vida dos indivíduos aí presentes, assim como no próprio meio social onde a Instituição está situada.

O atual chefe do DAA do IFPB-JP afirma que a permanência de trabalhadoras terceirizadas no cargo por longos períodos é consequência de uma estratégia adotada pelas empresas vencedoras das licitações. Segundo ele, assim que os processos licitatórios são concluídos, a empresa vitoriosa entra em contato com as trabalhadoras para saber se elas possuem interesse em permanecer no trabalho e seguir adiante com suas atividades. O principal benefício para a empresa é que ela não tem a necessidade de treinar e capacitar uma nova funcionária para aquela função, pois a alteração (rotatividade) foi por parte da empresa e não das trabalhadoras.

Ainda segundo o responsável pelo DAA, a direção do IFPB-JP não tem qualquer tipo de ingerência sobre as empresas contratadas, seja em seu quadro funcional ou em como os processos seletivos são realizados. O chefe do DAA argumenta que o departamento segue estritamente os princípios de uma gestão republicana dentro de um Estado moderno, ou seja, as ações são orientadas pela impessoalidade, probidade, moralidade, transparência e o universalismo de procedimentos. Contudo, admite que, indiretamente, o instituto se favorece com a manutenção dessas trabalhadoras, haja vista que esse fato erradica eventuais problemas de continuidade em serviços que são de primeira ordem para o funcionamento do órgão educacional em questão.

Silveira, o responsável pela ZÊLO, confirma quase que na íntegra, a versão narrada pela chefia do DAA. A única divergência entre os relatos é que, segundo Silveira, existe a intenção por parte do Instituto em assegurar a manutenção dessas trabalhadoras em suas funções. Para ele, esse desejo é manifestado de forma implícita às empresas vencedoras da licitação, pois a chefia do DAA apresentou todo o quadro de funcionárias terceirizadas e comentou sobre os bons serviços prestados por elas. Isso seria, para ele, 
um indicador da vontade por parte do Instituto em assegurar a permanência dessas trabalhadoras.

Entretanto, é bom destacar que tanto o processo para contratação dessas empresas prestadoras de serviços quanto a fiscalização das atividades desenvolvidas por elas, são de fato todo regidos por um aparato de leis, portarias e instruções normativas que visam garantir o máximo de transparência, isonomia, impessoalidade, moralidade e probidade para todo o trâmite.

\section{Considerações finais}

Um primeiro apontamento importante para explicar a permanência de trabalhadoras terceirizadas por períodos extensos em suas funções é, obviamente, que seus serviços são indispensáveis para o funcionamento do IFPB-JP. Esse argumento ganha mais força quando se recorda o exemplo da Universidade do Estado do Rio de Janeiro (UERJ), onde as empresas prestadoras de serviços interromperam suas atividades por que a universidade não honrou os contratos, e consequentemente, o início do ano letivo de 2017 foi suspenso. Um trecho da nota publicada pela Reitoria da UERJ explicita rigorosamente isso:

As condições de manutenção da universidade degradam-se cada vez mais com o não pagamento das empresas terceirizadas, contratadas por meio de licitação pública: limpeza, vigilância e coleta de lixo estão restritas, além de o Restaurante Universitário permanecer fechado (UERJ..., 2017).

A condição de trabalhadora terceirizada, como algo que não faz parte integralmente do espaço e da estrutura do IFPB-JP, precisa ser revista com urgência e muita atenção. Com base em dados levantados no próprio Instituto, por meio de uma pesquisa em documentos, assim como de um processo de interação e observação participante com as terceirizadas, busquei demonstrar como essas elas são legítimas profissionais da educação. Portanto, devem ser reconhecidas como alguém que tem participação ativa e decisiva nas práticas educativas edificadoras da história dessa instituição de ensino, pesquisa e extensão.

Ao observar a intersecção entre trabalho terceirizado e gênero, fica nítida a ligação entre as atividades corriqueiramente terceirizadas, inclusive pela própria estrutura do arcabouço jurídico que regulamenta essa modalidade de subcontrato, com o chamado trabalho reprodutivo social. Este último abarca as atividades domésticas, de asseio e 
limpeza, assim como a reprodução material da força de trabalho humana. Sendo assim, nota-se que

[...] o capital tem sabido também se apropriar intensificadamente da polivalência e multiatividade do trabalho feminino, da experiência que as mulheres trabalhadoras trazem das suas atividades realizadas na esfera do trabalho reprodutivo, do trabalho doméstico (ANTUNES, 2009, p. 109, grifos do autor).

Reforçando que as origens da opressão sobre as mulheres não é algo restrito ao capitalismo, mas sim de uma série de preconceitos que estruturam a sociedade em uma perspectiva, masculinista, machista e que "o fim da sociedade de classes não significa direta e imediatamente o fim da opressão de gênero" (ANTUNES, 2009, p. 110).

Outro importante ponto a ser observado é a pequena divergência entre Silveira, responsável pela ZÊLO, e o chefe do DAA, a respeito do porquê da permanência das trabalhadoras no cargo apesar da rotatividade das empresas. É importante notar que o responsável pelo DAA é funcionário público de carreira, chefe de setor, logo é um indivíduo cercado por regras e normas o que o faz agir conforme seu habitus profissional. Somado a isso, ele não responde simplesmente por si só, como um "cidadão comum" emitindo sua opinião, mas sim por todo um setor, um departamento de uma autarquia federal.

Diferente da situação descrita anteriormente, Silveira é funcionário da iniciativa privada, não está em um contrato tão normatizado como o de um servidor público. Por isso, entre outros fatores, que aqui não cabe considerar, era mais objetivo em seus diálogos ao se referir às relações entre a chefia do DAA e as trabalhadoras terceirizadas, e não fez questão nenhuma de esconder sua opinião sobre o possível desejo por parte da gestão do Instituto em mantê-las em suas respectivas funções.

Urge destacar que este trabalho foi pensado e estruturado de forma que pudesse dar visibilidade a essa parcela importante do quadro de trabalhadoras que compõem o IFPB-JP, aqui especialmente representada por Olga e Marli.

Não obstante, é fato que não só por meio de reconhecimento simbólico se garante a condição de dignidade que essas trabalhadoras de fato almejam. Existe ainda uma série de barreiras que as impede de ocupar uma posição semelhante à das servidoras estatutárias. Barreiras essas que não são apenas salariais, mas também ligadas ao fato de estarem sob um contrato trabalhista que não lhes dá a mesma proteção social que suas 
colegas estatutárias. Por isso, faz-se necessário, por parte da gestão do IFPB-JP, a elaboração de políticas internas compensatórias a fim de diminuir as assimetrias provocadas pela coexistência de trabalhadoras que desempenham a mesma função, mas estão sob a vigência de contratos distintos.

Aqui é preciso deixar evidente que não se tenta em nenhum momento construir a imagem de que o servidor público é privilegiado, como o pensamento neoliberal insiste, de maneira vulgar e errônea, em afirmar, mas sim de objetivar a imperiosa necessidade de produzir um melhor entendimento sobre a situação das trabalhadoras terceirizadas, que apesar de ocuparem posições centrais para funcionalidade da Instituição estão numa situação mais precária que os estatutários, propiciando, de certa forma, uma ferramenta para reflexões críticas não só para o campo acadêmico, mas também que fomentem possíveis ações de cunho político e/ou reivindicatório, voltadas à sua valorização e qualidade de vida. Essas medidas, por si só, podem ajudar a frear a tendência de precarização do funcionalismo público pela via da terceirização, se revelando assim uma importante bandeira para o movimento sindical, em sua totalidade, se apropriar e buscar construir pautas mais combativas, enfrentando a classe política e a classe patronal, buscando soluções práticas e efetivas para sanar essas demandas sociais.

Para concluir, reforço que os desafios à classe trabalhadora, em especial às trabalhadoras terceirizadas da educação, impostos pela atual conjuntura política, são de grande relevância. A ascensão de um governo com perfil político reacionário, em combinação com diretrizes econômicas neoliberais, deve ser vista como um obstáculo a ser removido o quanto antes. Tal empreendimento pode não ter caminho fácil de ser percorrido, mas está na ordem do dia para o movimento sindical, movimento estudantil e demais movimentos sociais comprometidos com uma transformação social justa.

\section{Referências}

ABRAMO, Laís. Desafios atuais da sociologia do trabalho na América Latina: algumas hipóteses para a discussão. In: TOLEDO, E. de la G. (Org.). Los retos teóricos de los estudios del trabajo hacia el siglo XXI. Buenos Aires: CLACSO, Consejo Latinoamericano de Ciencias Sociales, 1999, p. 11-24. Disponível em: 
http://biblioteca.clacso.edu.ar/clacso/gt/20101102025132/3abramo.pdf. Acesso em: 30/04/20.

ABRAMO, Laís. Desigualdades de gênero e raça no mercado de trabalho brasileiro. Ciência e Cultura. São Paulo, v. 58, n. 04, p. 40-41, 2006. Disponível em: $\mathrm{http}: / /$ cienciaecultura.bvs.br/scielo.php?script=sci_issuetoc\&pid=0009-672520060004\& lng=pt\&nrm=iso. Acesso em: 30/04/20.

ALVES, Giovanni. O novo (e precário) mundo do trabalho: reestruturação produtiva e crise do sindicalismo. São Paulo: Boitempo Editorial, 2000.

ANTUNES, Ricardo. Os sentidos do trabalho: ensaio sobre a afirmação e a negação do trabalho. 3. ed. São Paulo: Boitempo Editorial, 2009.

ANTUNES, Ricardo. O continente do labor. São Paulo: Boitempo, 2011.

BRASIL. Presidência da República. Decreto-lei No 200, de 25 de fevereiro de 1967. Brasília: Presidência da República, 1967. Disponível em: http://www.planalto.gov.br/ ccivil_03/decreto-lei/del0200.htm. Acesso em: 30/04/20.

BRASIL. Presidência da República. Lei 6.019 de 03 de janeiro de 1974. Brasília: Presidência da República, 1967. Disponível em: http://www.planalto.gov.br/ ccivil_03/leis/16019.htm. Acesso em: 30/04/20.

BRASIL. Presidência da República. Lei 7.102 de 20 de junho de 1983. Brasília: Presidência da República, 1967. Disponível em: http://www.planalto.gov.br/ ccivil_03/LEIS/L7102.htm. Acesso em: 30/04/20.

BRASIL. Tribunal Superior do Trabalho. Súmula 331. Contrato de prestação de serviços. Legalidade (nova redação do item IV e inseridos os itens V e VI à redação) - Res. 174/2011, DEJT divulgado em 27, 30 e 31 de mai. de 2011. Brasília: TST, 1993. Disponível em: http://www3.tst.jus.br/jurisprudencia/Sumulas_com_indice/Sumulas_ Ind_301_350.html. Acesso em: 30/04/20.

CARVAlHO, José Murilo de. Cidadania no Brasil: o longo caminho. 15. ed. Rio de Janeiro: Civilização Brasileira, 2012.

DIEESE. Impactos da Lei 13.429/2017(Antigo PL 4302/1998) para os trabalhadores: contrato de trabalho temporário e terceirização. Nota Técnica. São Paulo, n. 175, p. 0113, 2017. Disponível em: https://www.dieese.org.br/notatecnica/2017/notaTec175 TerceirizacaoTrabalhoTemporario.pdf. Acesso em: 08/11/18.

LEITE, Márcia de Paula. A sociologia do trabalho na América Latina: seus temas e problemas (re)visitados. Sociologia \& Antropologia. Rio de Janeiro, v. 2, n. 04, p. $103-$ 127, 2012. Disponível em: https://www.scielo.br/scielo.php?script=sci_arttext\&pid= S2238-38752012000400103. Acesso em: 30/04/20.

MARCELINO, Paula; CAVALCANTE, Sávio. Por uma definição de terceirização. Caderno CRH, Salvador, v. 25, n. 65, p. 331-346, 2012. Disponível em: https:// www.scielo.br/scielo.php?script=sci_arttext\&pid=S0103-49792012000200010. Acesso em: 30/04/20. 
MARINI, R. M. Dialética da dependência. In: TRASPADINI, R.; STEDILE, J. P. (Orgs.). Ruy Mauro Marini: vida e obra. São Paulo: Expressão Popular, 2005, p. 137-180.

NOGUEIRA, Cláudia M.; PASSOS, Rachel G. O fenômeno da terceirização e a divisão sociossexual e racial do trabalho. Revista Katálysis. Florianópolis, v. 21, n. 3, p. 484493, 2018. Disponível em: https://www.scielo.br/scielo.php?script=sci_abstract\&pid $=\mathrm{S} 1414-49802018000300484 \& \operatorname{lng}=$ pt\&nrm=iso. Acesso em: 30/04/20.

OLIVEIRA, Roberto Véras de. Sindicalismo e terceirização no Brasil: pontos para a reflexão. Caderno CRH, Salvador, v. 28, n. 75, p. 545-567, 2015. Disponível em: https://www.scielo.br/scielo.php?script=sci_arttext\&pid=S0103-49792015000300545.

Acesso em: 30/04/20.

OLIVEIRA, Ricardo G. Regulamentação da terceirização no Brasil: novas configurações das relações de trabalho, novos desafios à ação sindical. Revista de Ciências Sociais Século XXI, Santa Maria, v. 8, n. 2, p. 519-562, jul./dez. 2018. Disponível em: https://periodicos.ufsm.br/seculoxxi/article/view/36153. Acesso em: 30/04/20.

UERJ volta a adiar início das aulas por 'condições precárias'. Portal R7. São Paulo, 01/08/2017. Disponível em: https://noticias.r7.com/sao-paulo/uerj-volta-a-adiar-iniciodas-aulas-por-condicoes-precarias-01082017. Acesso em: 30/04/20.

PRONI, M. W.; GOMES, D. C. Precariedade ocupacional: uma questão de gênero e raça. Estudos Avançados, São Paulo, v. 29, n. 85, p. 137-151, 2015. Disponível em: https://www.scielo.br/scielo.php?script=sci_arttext\&pid=S0103-40142015000300010.

Acesso em: 30/04/20.

SANTOS, Elisabete Figueroa dos; DIOGO, Maria Fernanda; SHUCMAN, Lia Vainer. Entre o não lugar e o protagonismo: articulações teóricas entre trabalho, gênero e raça. Cadernos de Psicologia Social do Trabalho, São Paulo, v. 17, n. 1, p. 17-32, 2014. Disponível em: http://www.revistas.usp.br/cpst/issue/view/8475. Acesso em: 30/04/20.

Recebido em: 20/02/20.

Aceito em: 30/04/20. 